\title{
LEUCEMIA DE CÉLULAS PLASMÁTICAS: \\ UM RELATO DE CASO
}

\author{
Categoria Clínico
}

\section{CENTRO UNIVERSITÁRIO SÃO CAMILO}

Rodrigo Hernandes Togni Alves

Victor Hugo Monfrin Torres

Igor Barreto Ferreira

Antonio Daniel Marcovicchio

Paula Meirelles Silva

Isabella Furquim de Souza

Email: isabelafurquim@uol.com.br Telefone: (11)973236884

Endereço: Rua Ribeiro do Amaral, 585 - Apartamento 102 - São Paulo-SP 
LEUCEMIA DE CÉLULAS PLASMÁTICAS:

UM RELATO DE CASO

COMUSC VI - Categoria Clínico

DESCRITORES: Leucemia Plasmocitária. 


\title{
LEUCEMIA DE CÉlULAS PLASMÁTICAS:UM RELATO DE CASO
}

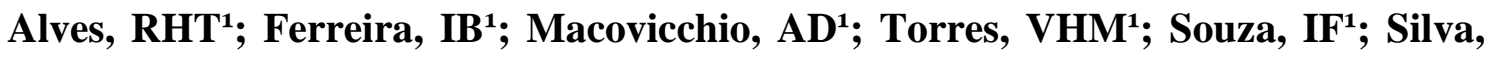 \\ PM' ; Medeiros; JE²;
}

\section{AUTORES}

\section{ORIENTADOR}

\section{RESUMO:}

INTRODUÇÃO: A leucemia de células plasmáticas (LCP) é uma desordem linfoproliferativa muito rara. Seu diagnóstico é realizado com a presença de $>20 \%$ de plasmócitos no sangue periférico ou > de 2000 plasmócitos $/ \mathrm{mm}^{3}$ com imunofenotipagem confirmando clonalidade. A leucemia de células plasmáticas pode ser primária, quando ocorre sem o antecedente de mieloma múltiplo (MM) ou secundária quando é uma evolução rara e agressiva do MM, tendo uma proporção de $60 \%$ e $40 \%$ respectivamente. A expectativa de vida sem tratamento é de aproximadamente de 12 meses. A maior incidência ocorre na sexta década de vida em homens e afrodescendentes. As principais manifestações são: insuficiência renal, comprometimento da medula óssea e suas séries (anemias, plaquetopenia e citopenia), efusão pleural e comprometimento neurológico.

OBJETIVOS: Relatar caso de LCP Primária, sua evolução e complicações e elucidar a Leucemia de células plasmáticas através da literatura

METODOLOGIA: Para o desenvolvimento deste trabalho foram consultados as planilhas e o livro de registros durante estagio da disciplina do curso de medicina.

DESCRIÇÃO DO CASO: 59 anos, mulher, apresentou queixa de náuseas, vômitos, adinamia, prostração e sangramento em cavidade oral além de petéquias e equimoses ao exame físico. Foram realizados hemogramas que revelaram bicitopenia e leucocitose. No terceiro dia de internação a paciente evoluiu com insuficiência respiratória aguda, com presença de infiltrado pulmonar, sendo tratada com antibioticoterapia, houve também insuficiência renal aguda e eliminação de banda monoclonal $\mathrm{IgG}$ em urina de 24 horas. A imunofenotipagem de sangue periférico revelou a presença de $70 \%$ de células com aberrações fenotípicas e expressão de marcadores de linhagem plasmocitária. Ao quinto dia apresentou hemorragia alveolar com consequente piora, insuficiência respiratória e instabilidade hemodinâmica evoluindo a óbito no sexto dia.

CONCLUSÃO: A LCP é uma patologia agressiva e rara, podendo levar o paciente a óbito em poucos dias. É indispensável reconhece-la, diagnostica-la e saber manejar as suas complicações para uma melhor qualidade de vida e melhora da sobrevida do paciente. 


\section{LEUCEMIA DE CÉLULAS PLASMÁTICAS: UM RELATO DE CASO \\ 1. INTRODUÇÃO:}

A leucemia de células plasmáticas (LCP) é uma neoplasia hematológica rara sendo responsável por $2 \%$ a $3 \%$ de todas as discrasias plasmocitárias. O diagnóstico é confirmado quando há presença células plasmáticas clonais excedendo 2x109/ L e/ou maior do que $20 \%$ do diferencial de leucócitos no sangue periférico ${ }^{1,2}$.

Clinicamente a LCP pode ser subdividida em dois tipos, a LCP primária (LCPp) e a LCP secundária (LCPs), a qual é decorrente da transformação leucêmica em um contexto de mieloma múltiplo existente. A forma primária perfaz cerca de $60-70 \%$ dos casos e a secundária $30-40 \%{ }^{3,4}$.

Este relato de caso aborda uma paciente com LCPp que teve início agudo e rápida evolução dos sintomas, incluindo sintomas clássicos de neoplasia de células plasmáticas como insuficiência renal aguda em progressão e sintomas variantes. A análise hematológica e citometria de fluxo são imprescindíveis para firmar o diagnóstico, principalmente quando se tem dados clínicos não conclusivos e morfologia celular atípica ${ }^{5}$.

\section{OBJETIVOS:}

O objetivo do trabalho é relatar um caso clínico de leucemia de células plasmáticas primária concomitante a revisão de literatura do tema.

\section{MÉTODOS:}

Para o desenvolvimento do estudo de caso, em acordo com a "Resolução 510 de 2016" foram coletadas informações referentes à paciente, através da análise de planilhas e do livro de registro do estágio da disciplina de hematologia da faculdade Centro Universitário São Camilo, por parte dos alunos enquanto orientados pelo professor e orientador da disciplina.

A revisão da literatura ocorreu por meio das informações obtidas através da base de dados PubMed, onde foram encontrados 110 artigos dos quais foram selecionados seis, devido ao fato de estarem de acordo com o objetivo do trabalho, permitindo melhor abordagem do tema, bem como fomentar a discussão. 
Os descritores utilizados para a pesquisa foram: plasma cell leukemia case report. Foram incluídos artigos em inglês e em português, publicados no período de 2013 a 2018 (últimos 5 anos), tanto gratuitos, quanto não gratuitos, estando de acordo com os aspectos éticos referentes à produção de pesquisas científicas. Foram excluídos artigos que fugiam do tema, ou abordavam peculiaridades, como alterações cromossômicas e desfechos específicos da doença.

\section{RELATO DO CASO:}

Mulher de 59 anos apresenta náuseas, vômitos nos últimos 15 dias, associado a fraqueza e cansaço, além de pequenos sangramentos em cavidade oral, esquimoses e petéquias em dorso e tórax. Negou febre, sudorese ou linfodomegalia, além de demais comorbidades, relata retirada de cisto ovariano. Negou possuir alergias, hábitos e vícios, negou usar medicamentos.

Ao exame físico apresentou-se em regular estado geral, consciente e orientada em tempo e espaço, aniquitérica, acianótica e afebril, hipocorada $++/ 4$, com petéquias em conjuntiva e desidratada $++/ 4$. Na orofaringe apresentou petéquias/purpuras em palato mole. Observou-se petéquias em tronco, abdômen e nos membros inferiores, as panturrilhas estavam livres.

Apresentou nos hemogramas, durante o período de internação, diminuição de hemoglobina (variando de $8,1-6,9$ ), leucocitose (flutuando entre os valores de 42500 29400), plaquetopenia (oscilando de 21 - 65mil) e EAS com proteinúria e cilindros hialinos. A paciente relatou melhora clínica após iniciar prednisona e realizar transfusão de plaquetas. Exame físico abdominal e renal não apresentavam nenhuma alteração digna de nota.

No segundo dia de internação, a paciente apresentou edema facial e tosse seca, negou dispneia e hiporexia, todavia com queda do estado geral. Ao exame físico evidenciou: regular estado geral, consciente e orientada no tempo e espaço, anictérico, acianótica e afebril, hipocorada $3+/ 4+$, hidratada, edema palpebral e facial, além de petéquias em palato mole e abdome. Aparelho respiratório apresentava: murmúrio vesicular positivo bilateralmente com estertores crepitantes finos em base. $\mathrm{O}$ abdômen era plano, sem visceromegalias, ruídos hidroaéreos positivos. Nos MMII's houve piora do edema, sem sinais de TVP. 
Suspeitou-se de leucemia aguda devido leucocitose e bicitopenia (anemia normocítica normocrômica) e plaquetopenia, além de apresentar insuficiência renal aguda com clearence creatina: $40.2 \mathrm{ml} / \mathrm{min}$.

No terceiro dia de internação na enfermaria, a paciente iniciou quadro de insuficiência respiratória hipoxêmica, associado a infiltrado pulmonar, sendo administrado antibioticoterapia de amplo espectro. No mesmo dia foi constatado piora da insuficiência renal aguda. A análise imunofenotípica de sangue periférico revelou a presença de $70 \%$ de células com fenótipo aberrante e expressão dos marcadores de linhagem plasmocitária CD38 e CD138.

Ao quinto dia paciente evoluiu com hemorragia alveolar sendo transferida para a UTI, apresentando piora do quadro com instabilidade hemodinâmica e piora do quadro respiratório. No sexto dia de internação, paciente apresentou Hemorragia alveolar com broncoespasmo refratário ao tratamento, evoluindo para parada cardiorrespiratória que não apresentou resposta a intervenção da equipe e consequentemente óbito.

\section{DISCUSSÃO DA LITERATURA:}

A LCP é uma rara condição onco-hematológica, extremamente agressiva com duas formas de apresentação, sendo elas, a forma primária e a secundária. A primária apresenta-se como uma leucemia aguda. Em ambas as formas. o tratamento envolve quimioterapia associando inibidores de proteossoma, imunomoduladores e corticóide, sendo descrito alguns esquemas na literatura, todavia, sem muito sucesso. São exemplos dessas drogas: Bortezomibe, Talidomida, Lenalidomida, Ciclofosfamida e Doxorrubicina $^{6}$. O transplante autólogo de medula óssea está indicado para pacientes elegíveis, em geral com menos de 65 anos (embora muitos centros já não considerem a idade isolada, e sim o status funcional, para realizar esse procedimento) e que apresentaram resposta com tratamento anterior. Apesar de algumas literaturas não avaliem o real impacto na sobrevida global, o transplante prolonga a sobrevida livre de doença e/ou a sobrevida livre de progressão.

A epidemiologia demonstra que a LCPp apresenta-se mais comumente em pacientes na sexta década de vida, já a LCPs costuma ter sua maior taxa de incidência em pacientes na sétima década de vida ${ }^{4,6}$. A prevalência ocorre discretamente em negros e em homens ${ }^{7,8}$, no caso a paciente somente se enquadra no perfil epidemiológico da idade, fugindo do restante. 
A LCPp possui em seu espectro de apresentação: anemia, leucocitose, trombocitopenia e hepatoesplenomegalia; sendo uma apresentação típica de leucose aguda, no caso relatado observávamos que todos estes sinais estavam presentes na paciente, exceto pelo último. As citopenias resultam na diminuição dos níveis de linfócitos T CD4 e de neutróficos, as quais associadas a hipogamaglobulinemia funcional (visto que a proteína $M$ não possui função biológica) culminam na disfunção da imunidade celular, inata e humoral deixando os pacientes susceptíveis a infecções, sendo este o maior motivo de procura do paciente ao pronto socorro. ${ }^{7,8}$

Os agentes infecciosos mais comuns nas fases precoces da doença são os microorganismos encapsulados, como o Streptococcus pneumoniae e o Haemophilus influenzae (reflexo da hipogamaglobulinemia). Infecções por gram negativos também são comuns. Além do quadro infeccioso, células plasmáticas no diferencial do leucograma, aumento dos níveis de LDH e beta-2 microglobulina são resultados que tem alta sugestividade de LCP. Já na LCPs podemos ter ao diagnóstico as manifestações clínicas semelhantes ao MM como hipercalcemia, disfunção renal, anemia, lesões ósseas líticas com dor óssea e alterações neurológicas. O diagnóstico da LCP ocorre quando no sangue periférico há presença de > 20\% de plasmócitos no sangue periférico ou > de 2000 plasmócitos $/ \mathrm{mm}^{3}$ com imunofenotipagem confirmando clonalidade. Ao se levantar a hipótese diagnóstica de LCP a investigação perpassa pela eletroforese de proteínas séricas, imunofixação, imunofenotipagem de sangue periférico e se houver necessidade, biopsia de medula óssea ou mielograma e imunofenotipagem de sangue medular ${ }^{4,7,9}$. Os achados da eletroforese de proteínas séricas e da urina de $24 \mathrm{~h}$, geralmente, demonstram a produção de imunoglobulinas monoclonais com imunofixação das seguintes imunoglobulinas $\operatorname{IgG}(33 \%), \operatorname{IgA}(20 \%), \operatorname{IgD}(3 \%)$ ou $\operatorname{IgE}(1 \%)^{4,6}$. A biopsia pode evidenciar a substituição das células responsáveis pela hematopoese normal pelas células plasmáticas clonais. A imunofenotipagem, como já visto anteriormente, é um exame fundamental para o diagnóstico, entre os seus marcadores temos tipicamente a expressão de CD138 e de CD38, os quais estavam presentes na paciente do caso. ${ }^{1,4,7}$

Devido à escassez de material de relevância na literatura, e ao realizar-se a busca literária sobre o tema em outros relatos de casos e outros pequenos estudos, tem-se utilizado o tratamento do MM para a LCP. O esquema quimioterápico se baseia em Bortezomibe, estando presente na maior parte dos esquemas de quimioterapia para a LCP, tendo melhores resultados na LCPp10. Além disso, pode-se realizar transplante autólogo 
de células hematopoiéticas se o paciente for elegível, porém, devido a um hiato na literatura, não há um protocolo estabelecido para a realização do transplante, o aconselhável é a individualização de cada caso ${ }^{4,11}$.
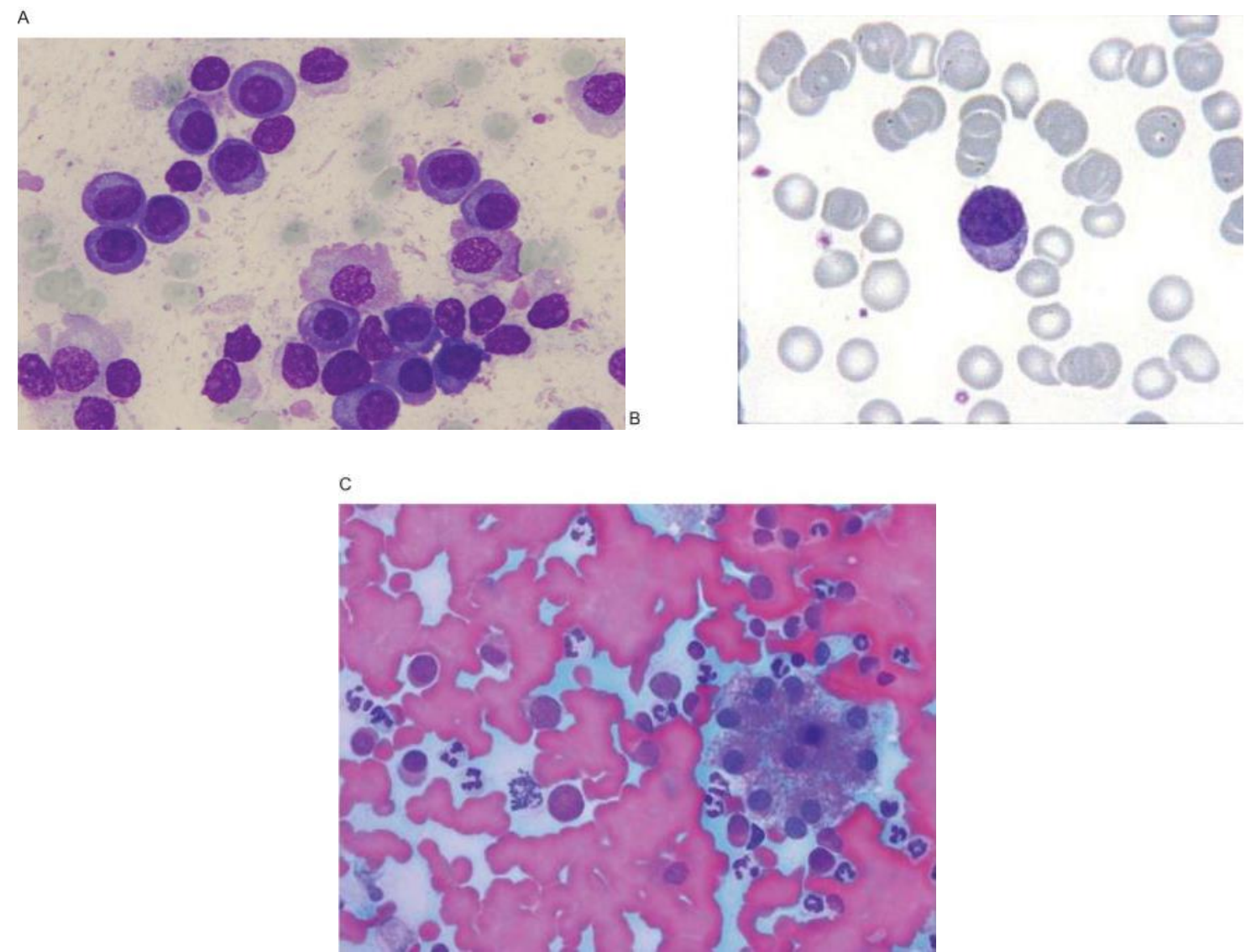

Imagem (A) demonstra morfologia convencional de LCP evidenciando infiltração de medula óssea. Imagem (B) mostra célula plasmática circulante. Imagem (C) nos revela os frequentes envolvimentos extra medulares (Infiltrado hepático). ${ }^{4}$

\section{CONCLUSÃO:}

A LCP é uma neoplasia hematológica rara e agressiva, principalmente na sua forma primária. A utilização de quimioterápicos e transplante autólogo, com o uso de drogas ainda em estudo são opções de tratamento atuais e vem aumentando a sobrevida de pacientes com LCP, quando iniciados precocemente, entretanto a sobrevida ainda continua sendo baixa.

É indispensável o diagnóstico precoce da doença, assim como também o início do tratamento, para que o desfecho não seja dramático e com baixa sobrevida em curto prazo. 
Como o tratamento da LCP não possui um protocolo exato, com os poucos medicamentos específicos, os pacientes não obtêm tantos benefícios com os tratamentos disponíveis. Sendo assim, fomenta-se a busca cientifica sobre o tema, com maiores níveis de evidências e alternativas farmacológicas. ${ }^{4,11}$.

\section{REFERÊNCIAS:}

1. Kyle RA, Maldonado JE, Bayrd ED. Plasma cell leukemia. Report on 17 cases. Arch Intern Med 133: 813-818, (1974)

2. Sher T, Miller KC, Deeb G, Lee K, Chanan-Khan A. Plasma cell leukaemia and other aggressive plasma cell malignancies. $\mathrm{Br} \mathrm{J}$ Haematol, 150: 418-427, (2010 3. Gangadhar P, Ahmed Z, Pai MR, Sandhya I. Primary plasma cell leukemia: A report of two cases of a rare and aggressive variant of plasma cell myeloma with the review of literature. Indian J Pathol Microbiol. ;59:541-4, (2016) 4. Fernández de Larrea C, Kyle RA, Durie BG, Ludwig H, Usmani S, et al. Plasma cell leukemia: Consensus statement on diagnostic requirements, response criteria and treatment recommendations by the International Myeloma Working Group. Leukemia; 27:780-91,

5. Evdoxia Gounari et al. Utility of Hematology Analyzer and Flow Cytometry in Timely and Correct Detection of Circulating Plasma Cells: Report of Three Cases. International clinical cytometry society, (2016) 6. Tiedemann RE, Gonzalez-Paz N, Kyle RA, Santana-Davila R, Price Troska T, Van Wier SA, et al. Genetic aberrations and survival in plasma cell leukemia. Leukemia. 2008;22(5):1044-52.

7. Wd T, Brambilla E, Hermelink HK, Eds HCC, Eble JN, Sauter G, et al. World Health Organization Classification of Tumours This book and all other volumes of the series can be purchased: From all countri es. 2008;(4th edition):167-78. 8. Ramsingh G, Mehan P, Luo J, Vij R, Morgensztern D. Primary plasma cell leukemia: A surveillance, epidemiology, and end results database analysis between 1973 and 2004. Canlcer. 2009;115(24):5734-9. 9. Gonsalves WI. Primary Plasma Cell Leukemia: A Practical Approach to Diagnosis and Clinical Management. 13(3):21-5. 10. Donk N Van De, van de Donk NWCJ, Lokhorst HM, Anderson KC, Richardson PG. How I treat plasma cell leukemia. Blood [Internet]. 2012;120(12):2376-89. Available from: http://www.pubmedcentral.nih.gov/articlerender.fcgi?artid=3757364\&tool= 11. Musto P. Progress in the Treatment of Primary Plasma Cell Leukemia. J Clin Oncol [Internet]. 2016;34(18):2082-4. Available from: http://jco.ascopubs.org/cgi/doi/10.1200/JCO.2016.66.6115 